\title{
Hubungan Self Regulated Learning dengan Flow Akademik Siswa
}

\author{
Satria Wati ${ }^{1}$, Firman $^{2}$ \\ ${ }^{12}$ Universitas Negeri Padang \\ *Corresponding author, e-mail: satriawati13@yahoo.com
}

\begin{abstract}
Abstrak
Dewasa ini ditemukan siswa tidak fokus dalam belajar dan mengerjakan tugas karena kurangnya pengaturan diri dalam belajar. Penelitian ini bertujuan untuk mengungkapkan (1) self regulated learning siswa, (2) flow akademik siswa dalam belajar, (3) menguji hubungan self regulated learning dengan flow akademik siswa. Penelitian ini menggunakan pendekatan kuantitatif dengan metode deskriptif korelasional. Populasi penelitian sebanyak 853 siswa SMA. Jumlah sampel 272 siswa, yang diperoleh dengan teknik Stratified Random Sampling. Instrumen yang digunakan yaitu angket tentang self regulated learning dan flow akademik dengan model skala Likert. Teknik analisis data yaitu teknik deskriptif dengan rumus persentase dan teknik korelasional dengan rumus Pearson Product Moment Correlations. Hasil penelitian mengungkapkan (1) self regulated learning siswa berada pada kategori tinggi (2) flow akademik siswa berada pada kategori sedang (3) dan terdapat hubungan yang signifikan antara self regulated learning dengan flow akademik siswa.
\end{abstract}

Kata kunci: Self Regulated Learning, FlowAkademik.

This is an open access article distributed under the Creative Commons 4.0 Attribution

License, which permits unrestricted use, distribution, and reproduction in any medium, provided the original work is properly cited. (C2017 by author and UniversitasNegeri Padang.

\section{PENDAHULUAN}

Keberhasilan tujuan pendidikan tergantung kepada proses yang dilalui oleh siswa sebagai salah satu unsur dalam proses belajar. Melalui belajar siswa memperoleh suatu pengalaman, baik itu berupa perubahan tingkah laku, keterampilan, nilai, dan sikapnya. Belajar adalah serangkaian kegiatan jiwa dan raga untuk memperoleh suatu perubahan tingkah laku sebagai hasil dari pengalaman individu dalam berinteraksi dengan lingkungannya yang meliputi kognitif, afektif, dan psikomotornya, dengan kata lain belajar merupakan perubahan yang dialami individu, baik perubahan tingkah laku, cara berpikir, keterampilan bahkan pribadi yang merupakan hasil dari latihan dan pengalaman, di mana perubahan itu nantinya bisa mempengaruhi pola pikir individu untuk bertindak (Syaiful Bahri Djamarah, 2011). Belajar bertujuan agar kemampuan yang ada pada diri siswa dapat berkembang secara optimal. Tujuan belajar ini dapat tercapai dengan hasil yang maksimal jika siswa dapat mengikuti proses pembelajaran dengan baik. Akan tetapi, dalam proses pembelajaran siswa sering mengalami kejenuhan atau pun merasa bosan ketika melakukan kegiatan yang bersifat akademik seperti dalam kegiatan belajar dan mengerjakan tugas, untuk menghilangkan kejenuhan atau pun kebosanan tersebut hal yang sering mereka lakukan yaitu dengan bermain hp, berbicara dengan teman yang ada di dekatnya, mengganggu teman, bahkan tidur saat belajar.

Seorang siswa yang mengalami kejenuhan dalam belajar menunjukkan tidak adanya kemajuan dalam belajarnya (Syah, 2012). Padahal, dalam mengikuti suatu kegiatan agar bisa memperoleh hasil yang maksimal diperlukan suatu kondisi yang disebut sebagai flow. Keadaan ketika seseorang bisa fokus atau terhanyut sepenuhnya pada kegiatan yang dilakukannya, seluruh perhatiannya tercurahkan pada kegiatan tersebut dinamakan dengan flow (Prawitasari Johana. E, 2012). Siswa yang mengalami flow mampu menikmati setiap aktivitasnya dengan perasaan senang, fokus terhadap apa yang dikerjakan, memiliki perasaan nyaman dalam melakukannya, memiliki motivasi yang baik yang berasal dari dirinya sendiri, serta merasa bahwa waktu sangat cepat berlalu ketika mengerjakan kegiatan ataupun pekerjaan tersebut.

Yuwanto menjelaskan keadaan flow pada saat siswa melakukan kegiatan yang berhubungan dengan bidang akademik, seperti mengikuti proses belajar dan pembelajaran dikelas serta mengerjakan tugas yang ada, disebut sebagai flow akademik (Arif, 2013). Siswa yang berada dalam situasi flow akademik akan mampu untuk 
melibatkan dirinya serta memiliki konsentrasi penuh terhadap pelajaran yang sedang dijalaninya dan akan menunjukkan antusiasnya dalam belajar. Hasil penelitian Yuwanto, Budiman, Prasetyo, \& Siandhika tentang "Stres Akademik dan flow Akademik" menunjukkan bahwa flow akademik mahasiswa berada pada kategori sedang yaitu 52,9\%, Ini menunjukkan tidak semua mahasiswa bisa mengalami flow, hal ini di sebabkan karena mereka mengalami stres akademik (Arif, 2013). Selanjutnya penelitian tentang "Religiusitas dengan Flow Akademik pada Siswa" menunjukkan bahwa flow akademik siswa berada pada kategori rendah dengan persentase 42,8\% (Arbi Alfarabi, Putri Saraswati, 2017). Kemudian penelitian tentang "Flow pada Siswa Sekolah Tinggi Teknologi Angkatan Darat" menunjukkan bahwa 50,8\% dari siswa STTAD berada pada kategori flow yang rendah (Rahimia, 2016).

Hal ini dapat disimpulkan bahwa banyak siswa yang flow akademiknya berada pada kategori rendah. Siswa yang memiliki flow akademik yang rendah menunjukkan antusias yang rendah ketika mengikuti proses belajar dan penyelesaian tugas akademiknya (Prihandrijani, 2016). Rendahnya flow akademik siswa dapat di pengaruhi oleh berbagai faktor, salah satu faktor yang mempengaruhi yaitu pengendalian diri (Mäkikangas, Bakker, Aunola, \& Demerouti, 2010). Zimmerman menjelaskan self regulated learning sebagai kemampuan siswa menerapkan strategi pembelajaran efektif dan bagaimana serta kapan menggunakan kemampuan untuk memotivasi diri sehingga tugas terselesaikan dengan memuaskan (Slavin. R, 2011). Artinya, siswa dapat dikatakan memiliki pengaturan diri dalam belajar apabila siswa memiliki strategi untuk mengaktifkan metakognitif, motivasi, dan tingkah laku dalam belajarnya. Ketika siswa mampu mengembangkan kemampuan self regulated learning, maka akan lebih mudah baginya untuk mengalami flow akademik.

Berdasarkan observasi yang dilakukan selama praktek lapangan bimbingan dan konseling di sekolah (PLBK-S) di SMA Adabiah Padang pada Tanggal 24 Juli 2017 sampai Tanggal 9 Desember 2017 diketahui bahwa ketika guru menjelaskan pelajaran, banyak ditemukan siswa yang keluar masuk kelas, berbicara dengan teman yang berada didekatnya, cabut saat jam pelajaran berlangsung, tidak berkonsentrasi dalam belajar, tidak antusias menjawab pertanyaan yang diajukan oleh guru, malas membuat catatan dan tugas, membuat tugas asalasalan, mengerjakan tugas mata pelajaran lain, menggunakan HP secara sembunyi-sembunyi, melamun ketika belajar, ketika guru memberikan soal latihan ada siswa yang memilih untuk menunggu temannya selesai mengerjakan latihan itu dan pada akhirnya mencontek tugas teman tersebut.

Selanjutnya wawancara yang dilakukan dengan 5 orang siswa di SMA Adabiah Padang pada Tanggal 22 Februari 2018 diperoleh informasi bahwa 3 dari 5 orang siswa ketika proses belajar-mengajar berlangsung mereka sering merasa bosan dengan materi pelajaran, merasa terbebani dengan tugas yang diberikan oleh guru, sulit untuk bisa berkonsentrasi ketika belajar, merasa guru kurang pandai dalam menjelaskan materi pelajaran, malas untuk memperhatikan guru menjelaskan karena menganggap materi yang disampaikan oleh guru tersebut tidak perlu, merasa tidak nyaman dalam belajar karena guru kurang tegas ketika di kelas seperti tidak memberikan sanksi yang tegas ketika siswa lain meribut di kelas.

Seorang siswa yang memiliki pengendalian/pengaturan diri dalam belajar (self regulated learning) yang bagus, maka akan lebih mudah bagi dirinya untuk bisa mengalami flow akademik. Hal ini didukung oleh hasil penelitian yang menyatakan seseorang akan mampu untuk mengerjakan tugasnya dengan baik dan mandiri apabila dalam proses mengikuti pembelajaran memiliki kemampuan meregulasi diri dalam menghadapi tugastugasnya (Rozali, 2014). Di sisi lain, para ahli kognitif sosial dan psikologi kognitif menyadari bahwa untuk bisa menjadi pembelajar yang benar-benar efektif, bisa fokus dengan kegiatan belajarnya, siswa harus mampu untuk terlibat dalam beberapa aktivitas mengatur diri (Ormrod, 2009). Berdasarkan data di atas, dapat dipahami bahwa masih ada beberapa siswa yang belum memiliki flow akademik yang dapat membuat mereka lebih bergairah atau bersemangat dalam belajar. Dari permasalahan yang telah diuraikan, peneliti tertarik untuk meneliti mengenai Hubungan Self Regulated Learning dengan Flow Akademik Siswa.

\section{METODE PENELITIAN}

Penelitian ini menggunakan pendekatan kuantitatif dengan metode deskriptif korelasional yang bertujuan untuk mendeskripsikan self regulated learning dan flow akademik siswa, serta menguji tingkat signifikansi hubungan self regulated learning dengan flow akademik siswa. Populasi penelitian yaitu siswa SMA Adabiah Padang yang terdaftar pada tahun ajaran 2018/2019 yang berjumlah 853 orang siswa dan sampel sebanyak 272 orang siswa yang dipilih dengan Stratified Random Sampling. Instrumen yang digunakan adalah angket tentang self regulated learning danflow akademik siswa. Data dianalisis dengan statistik deskriptif dan teknik Pearson Product Moment. 
HASIL PENELITIAN

Berdasarkan pengolahan data yang telah dilakukan, ditemukan hasil penelitian sebagai berikut;

1. Self Regulated Learning Siswa

Tabel 7. Distribusi Frekuensi dan Persentase Self Regulated Learning Siswa (n= 272 )

\begin{tabular}{|c|c|c|c|c|c|c|c|c|c|c|c|c|}
\hline \multirow{3}{*}{ No } & \multirow{3}{*}{ Sub Variabel } & \multicolumn{10}{|c|}{ Klasifikasi } & \multirow{3}{*}{ Keterangan } \\
\hline & & \multicolumn{2}{|c|}{ ST } & \multicolumn{2}{|c|}{$\mathbf{T}$} & \multicolumn{2}{|c|}{$\mathbf{S}$} & \multicolumn{2}{|c|}{$\mathbf{R}$} & \multicolumn{2}{|c|}{ SR } & \\
\hline & & f & $\%$ & f & $\%$ & f & $\%$ & f & $\%$ & f & $\%$ & \\
\hline 1 & Metakognitif & 25 & 9,19 & 153 & 56,25 & 88 & 32,35 & 6 & 2,21 & 0 & 0 & Tinggi \\
\hline 2 & Motivasi & 22 & 8,09 & 133 & 48,90 & 107 & 39,34 & 10 & 3,68 & 0 & 0 & Tinggi \\
\hline 3 & Perilaku & 42 & 15,44 & 128 & 47,06 & 87 & 31,99 & 14 & 5,15 & 1 & 0,37 & Tinggi \\
\hline & Keseluruhan & 21 & 7,72 & 148 & 54,41 & 99 & 36,40 & 4 & 1,47 & 0 & 0 & Tinggi \\
\hline
\end{tabular}

Tabel 7 menjelaskan bahwa secara keseluruhan self regulated learning siswa berada pada kategori tinggi dengan persentase sebesar 54,41\%. Ditinjau dari aspek metakognitif self regulated learning siswa berada pada kategori tinggi dengan persentase sebesar 56,25\%, pada aspek motivasi berada pada kategori tinggi dengan persentase sebesar 48,90\%, dan pada aspek perilaku juga berada pada kategori tinggi dengan persentase sebesar 47,06\%. Artinya sebagian besar siswa SMA Adabiah Padang sudah memiliki self regulated learning yang tergolong tinggi.

\section{Flow Akademik Siswa}

Hasil penelitian flow akademik siswa secara keseluruhan berada pada kategori sedang dengan persentase sebesar 50\%. Temuan penelitian dapat dilihat gambarannya sebagai berikut;

\section{Tabel 8. Distribusi Frekuensi dan Persentase Flow Akademik Siswa $(n=272)$}

\begin{tabular}{|c|c|c|c|c|c|c|c|c|c|c|c|c|}
\hline \multirow{3}{*}{ No } & \multirow{3}{*}{ Sub Variabel } & \multicolumn{10}{|c|}{ Klasifikasi } & \multirow{3}{*}{ Keterangan } \\
\hline & & \multicolumn{2}{|c|}{ ST } & \multicolumn{2}{|c|}{$\mathbf{T}$} & \multicolumn{2}{|c|}{$\mathbf{S}$} & \multicolumn{2}{|c|}{$\mathbf{R}$} & \multicolumn{2}{|c|}{ SR } & \\
\hline & & f & $\%$ & f & $\%$ & $\mathbf{f}$ & $\%$ & $\mathbf{f}$ & $\%$ & f & $\%$ & \\
\hline 1 & Absorption & 10 & 3,68 & 113 & 41,54 & 129 & 47,43 & 20 & 7,35 & 0 & 0 & Sedang \\
\hline 2 & Work Enjoyment & 0 & 0 & 67 & 24,63 & 168 & 61,76 & 36 & 13,24 & 1 & 0,37 & Sedang \\
\hline 3 & Intrinsic Work Motivation & 32 & 11,76 & 127 & 46,69 & 101 & 37,13 & 12 & 4,14 & 0 & 0 & Tinggi \\
\hline & Keseluruhan & 6 & 2,21 & 112 & 41,18 & 136 & 50 & 18 & 6,62 & 0 & 0 & Sedang \\
\hline
\end{tabular}

Tabel 8 menjelaskan bahwa secara keseluruhan flow akademik siswa berada pada kategori sedang dengan persentase sebesar 50\%. Ditinjau dari aspek absorption flow akademik siswa berada pada kategori sedang, dengan persentase sebesar $47,43 \%$. Selanjutnya pada aspek work enjoyment berada pada kategori sedang dengan persentase sebesar $61,76 \%$. Kemudian pada aspek intrinsic work motivation, flow akademik siswa berada pada kategori tinggi dengan persentase sebesar 46,69\%. Artinya, sebagian besar siswa SMA Adabiah Padang sudah memiliki flow akademik yang tergolong sedang.

\section{Hubungan Self Regulated learning dengan Flow Akademik Siswa}

Penelitian ini dilakukan untuk mengetahui ada tidaknya hubungan antara self regulated learning dengan flow akademik siswa. Hasil dari pengujian hipotesis mengungkapkan bahwa terdapat hubungan yang signifikan antara self regulated learning dengan flow akademik siswa dengan menggunakan perbandinganr $r_{\text {hitung }}$ sebesar $0,518>\mathrm{r}_{\text {tabel }} 0,117$ pada taraf kepercayaan $5 \%$. Hubungan yang signifikan ini dapat diartikan, semakin tinggi self regulated learning siswa maka tingkat flow akademik siswa semakin tinggi, sebaliknya, semakin rendah self regulated learning siswa maka tingkat flow akademik siswa semakin rendah juga.

\section{PEMBAHASAN}

\section{Self Regulated Learning Siswa}

Idealnya, seorang siswa perlu memiliki kemampuan self regulated learning yang baik. Siswa yang berprestasi tinggi seringkali adalah seorang pembelajar yang mampu meregulasi dirinya sendiri (Santrock, 2003). Dengan demikian, self regulated learning siswa masih harus ditingkatkan. Peningkatan self regulated learning dapat dilakukan oleh siswa dengan membiasakan diri untuk tekun dan berusaha dalam mengerjakan tugas-tugas belajar, menjaga motivasi belajar dan aktif dalam proses pembelajaran. Selanjutnya, untuk lebih jelasnya pembahasan mengenai kondisi self regulated learning siswa dapat dilihat melalui aspek berikut;

Aspek metakognitif berada pada kategori tinggi. Aspek ini berkaitan dengan merencanakan kegiatan belajar, memantau diri dalam kegiatan belajar, dan mengevaluasi diri dalam kegiatan belajar. Agar seorang siswa bisa memiliki self regulated learning yang baik, siswa tersebut hendaknya memiliki kemampuan metakognitif. Sebagaimana yang dikemukakan oleh Boekaerts tahap perencanaan berkaitan dengan prosesproses yang memiliki pengaruh yang mendahului usaha untuk bertindak serta proses dalam pembentukan 
tahap-tahap untuk mencapai tujuan yang telah ditetapkan (Susanto, 2006). Schank menambahkan bahwa pengetahuan mengenai kognisi meliputi perencanaan, pemantauan, dan perbaikan dari perilakunya. Sehingga, dengan demikian seorang siswa perlu meningkatkan kemampuan metakognitifnya agar memiliki self regulated learning yang baik (M. Nur Ghufron.,\& Risnawita, 2012).

Aspek motivasi berada pada kategori tinggi.Aspek ini berkaitan dengan kemandirian siswa dalam belajar, serta kepercayaan diri terhadap kemampuan dalam melakukan sesuatu. Sharing of information dalam pembelajaran telah terjadi perubahan, dari teacher centered learning menjadi student centered learning (Firman, 2016). Hal ini ditunjukkan adanya siswa yang sudah mampu untuk mandiri dalam belajar seperti mengerjakan tugas tanpa adanya bantuan dari orang lain, mencari sendiri informasi yang berkaitan dengan materi pelajaran melalui internet dan berbagai sumber lainnya, dengan kata lain guru bukanlah satu-satunya sumber pembelajaran tetapi berperan sebagai fasilitator dan motivator. Dengan kata lain, motivation to achive the goal or meet the standard, which in practice amounts to motivation to regulate the self". Artinya, bahwa motivasi diperlukan untuk mencapai tujuan atau memenuhi standar, yang dalam prakteknya motivasi diperlukan untuk mengatur diri (Baumeister \& Vohs, 2007).

Aspek perilaku berada pada kategori tinggi.Aspek ini berkaitan dengan mengatur diri dalam belajar dan menyeleksi sesuatu yang mendukung kegiatan belajar.Oleh sebab itu siswa perlu meningkatkan perilakunya dalam belajar. Hal ini sesuai dengan penelitian Hargis bahwa seseorang yang memiliki self regulated learning yang tinggi cenderung belajar dengan baik, mampu memantau, mengevaluasi dan mengatur belajarnya secara efektif, serta mampu menghemat waktu dalam menyelesaikan tugasnya.Selain itu, siswa juga perlu memiliki komitmen yang tinggi agar dapat menampilkan perilaku tersebut dengan baik seperti mencari sumber belajar, menggunakan pendekatan dalam belajar, dan menciptakan lingkungan belajar yang menyenangkan. Oleh karena itu, siswa perlu memiliki perilaku yang bagus dalam mendukung proses pembelajarannya (Rozali, 2014).

\section{Flow Akademik Siswa}

Flow akademik merupakan suatu unsur yang perlu dimiliki siswa dalam proses pembelajarannya. Flow yang dimaksud yaitu kondisi saat siswa dapat berkonsentrasi, munculnya rasa nyaman, memiliki motivasi yang berasal dari dirinya sendiri, serta menikmati aktivitas akademik yang dilakukan (Prihandrijani, 2016). Ciri-ciri ketika seseorang mengalami kondisi flow akademik seperti, merasakan kenyamanan dalam mengerjakan aktivitas dan ikut serta secara total dalam aktivitas tersebut. Sehingga tugas-tugas yang sedang dikerjakan menjadi mudah (Eni Purwati, 2016). Selanjutnya untuk lebih jelasnya pembahasan mengenai kondisi flow akademik siswa dapat dilihat melalui aspek berikut;

Aspek absorption berada pada kategori sedang. Aspek ini berkaitan dengan kondisi seseorang yang dapat berkonsentrasi penuh dimana semua perhatian dan konsentrasi terfokus pada kegiatan yang dilakukan serta menikmati aktivitas yang ada (Ignatius, 2013). Seseorang yang tidak bisa menikmati aktivitas belajarnya, maka dia lebih mudah untuk mengalami kebosanan. Oleh sebab itu siswa perlu mengembangkan dan mempertahankan aspek absorption yang dimiliki supaya dia lebih mudah untuk mengalami kondisi flow.

Aspek work enjoyment berada pada kategori sedang dengan persentase sebesar $61,76 \%$. Hal ini berarti beberapa siswa belum mampu untuk berpikir positif mengenai kegiatan yang dilakukannya. Bakker mengemukakan individu yang memiliki penilaian positif terhadap kegiatan yang dilakukannya mampu untuk melakukan kegiatan tersebut dalam jangka waktu yang lama (Eni Purwati, 2016). Oleh karena itu, siswa perlu memiliki penilaian positif terhadap kegiatan yang dilakukan, terutama dalam belajarnya.

Aspek intrinsic work motivation berada pada kategori tinggi.Aspek ini berkaitan dengan keinginan yang muncul dari dalam diri seseorang ketika dia melakukan aktivitas dengan tujuan agar memperoleh kesenangan dan kepuasan dari aktivitas yang dijalaninya (Bakker, dalam Robin Ignatius, 2013). Seseorang yang tidak memiliki motivasi dari dalam dirinya untuk mencapai kepuasan dalam belajarnya maka dia sulit untuk mengalami kondisi flow. Dalam hal ini, guru memiliki peran untuk membantu siswa dalam menumbuhkan semangat belajarnya seperti menggunakan metode dan sumber belajar yang mampu membuat siswa untuk lebih termotivasi lagi dalam belajar. Segala sesuatu yang berkaitan dengan kegiatan pembelajaran di dalam kelas menjadi wewenang dan tanggung jawab guru (Firman, 2009). Artinya, guru memiliki peranan penuh dalam membantu siswa untuk menumbuhkan motivasi belajar siswa. Oleh sebab itu, seorang siswa perlu memiliki motivasi dalam dirinya untuk belajar, sehingga dia lebih mudah untuk mencapai kesenangan ataupun kepuasan dari proses belajarnya.

\section{Hubungan Self Regulated learning dengan Flow Akademik Siswa}

Siswa yang berprestasi tinggi seringkali adalah seorang pembelajar yang mampu meregulasi dirinya sendiri (Santrock, 2007). Selanjutnya, seseorang yang memiliki self regulated learning yang baik, memiliki tujuan dalam belajar dan mampu mengembangkan emosi positif terhadap tugas (senang, puas, dan antusias), 
mampu mengontrol waktu dan memiliki usaha dalam menyelesaikan tugas, serta mampu untuk menciptakan lingkungan belajar yang menyenangkan (Montalvo dan Torres dalam Samarinda \& Alfina, 2014).

Hasil penelitian menjelaskan seseorang mampu untuk mengerjakan tugasnya dengan baik dan mandiri apabila dalam proses mengikuti pembelajaran memiliki kemampuan meregulasi diri dalam menghadapi tugas-tugasnya (Rozali, 2014). Namun, ketika seorang siswa memiliki flow akademik yang rendah maka siswa tersebut menunjukkan antusias yang rendah dalam belajar dan mengerjakan tugasnya (Prihandrijani, 2016).

Hasil penelitian menunjukkan bahwa setiap siswa mampu mencapai kondisi flow akademik, hanya saja pencapaiannya berbeda antara individu yang satu dengan individu yang lainnya. Oleh karena itu, tampaknya self regulated learning siswa selayaknya harus dimiliki oleh setiap siswa sebagai pengendali untuk mencapai kondisi flow akademik. Hal ini mengingat adanya hubungan antara self regulated learning dengan flow akademik siswa.

Berdasarkan pengujian korelasional yang menyatakan adanya hubungan yang signifikan antara self regulated learning dengan flow akademik siswa, maka seorang guru memiliki peran untuk membantu siswa dalam mempertahankan ataupun meningkatkan self regulated learning dan flow akademiknya. Usaha yang dapat dilakukan guru untuk meningkatkan self regulated learning siswa seperti mendorong siswa untuk menyusun beberapa tujuan belajarnya sendiri, memberikan kesempatan kepada siswa untuk belajar dan berprestasi tanpa arahan atau bantuan guru, memberikan umpan balik kepada siswa (Ormrod, 2009).

Selanjutnya, upaya yang dapat dilakukan guru BK untuk meningkatkan flow akademik siswa diantaranya, membantu siswa untuk meningkatkan kemampuan dalam menyelesaikan tantangan yang dihadapi, membantu siswa membuat tujuan yang jelas dalam belajar, serta membantu siswa untuk meningkatkan manajemen waktu dalam belajar. Jika seseorang dapat melaksanakan bentuk-bentuk usaha tersebut, maka mereka lebih mudah untuk mengatasi permasalahan yang dialami terutama yang berkatan dengan self regulated learning dengan flow akademik siswa (Silfa Agisni. S, 2017).

\section{KESIMPULAN}

Kesimpulan dalam penelitian ini yaitu; (1) Self regulated learning siswa secara keseluruhan berada pada kategori tinggi. Artinya, sebagian besar siswa sudah mampu untuk mengatur dirinya dalam belajar, (2) flow akademik siswa secara keseluruhan berada pada kategori sedang. Artinya, beberapa siswa belum mampu untuk mencapai kondisi flow ketika belajar maupun mengerjakan tugas, (3) terdapat hubungan yang signifikan antara self regulated learning dengan flow akademik siswa. Artinya, siswa yang memiliki self regulated learning yang tinggi maka flow akademik siswa juga tinggi. Begitu pula sebaliknya, jika self regulated learning siswa rendah maka flow akademik siswa juga rendah.

\section{Kepustakaan}

Arbi Alfarabi, Putri Saraswati, T. D. (2017). Religiusitas Dengan Flow Akademik Pada Siswa. Jurnal Psikologi Islami, 3(2), 145-154.

Baumeister, R. F., \& Vohs, K. D. (2007). Self-Regulation, Ego Depletion, and Motivation. Social and Personality Psychology Compass, 1(1), 115-128.

Eni Purwati, M. A. (2016). Hubungan Antara Self Efficacy Dengan Flow Akademik Pada Siswa Akselerasi SMPN 1 Sidoarjo. Jurnal Ilmiah Psikologi, 3(20), 249-260.

Firman. (2009). Tanggung Jawab Profesi Guru dalam Era Teknologi Informasi. Jurnal Ilmiah Ilmu Pendidikan, Vol IX No.

Firman. (2016). Peranan Psikologi dan Konseling dalam Peningkatan Kualitas Sumber Daya Manusia (SDM) Menuju Kesejahteraan Masyarakat Ekonomi Asean. Prosiding Asean Psychology \& Counselling Conference (APCC).

Ignatius, R. (2013). Go With the Flow: Dukungan Sosial dan Flow Akademik Pada Mahasiswa. Jurnal Ilmiah, 2(1), 1-19.

M. Nur Ghufron.,\& Risnawita, R. S. (2012). Teori-Teori Psikologi. Jogjakarta: Ar-Ruzz Media. 
Mäkikangas, A., Bakker, A. B., Aunola, K., \& Demerouti, E. (2010). Job resources and flow at work: Modelling the relationship via latent growth curve and mixture model methodology. Journal of Occupational and Organizational Psychology, 83(3), 795-814.

Ormrod, J. E. (2009). Psikologi Pendidikan: Membantu Siswa Tumbuh dan Berkembang. Jakarta: Erlangga.

Prawitasari Johana. E. (2012). Psikologi Terapan. Jakarta: Erlangga.

Prihandrijani, E. (2016). Pengaruh Motivasi Berprestasi dan Dukungan Sosial Terhadap Flow Akademik Pada Siswa SMA X di Surabaya. Tesis. Surabaya: Program Studi Magister Psikologi Fakultas Psikologi Universitas Erlangga.

Rahimia, N. (2016). Flow Pada Siswa Sekolah Tinggi Teknologi Angkatan Darat Kota Malang. Skripsi. Universitas Muhammadiyah Malang.

Rozali, Y. A. (2014). Hubungan Self Regulation Dengan Self Determination, 12(2), 61-66.

Samarinda, S. M. A. N., \& Alfina, I. (2014). Hubungan Self-Regulated Learning dengan Prokrastinasi Akademik pada Siswa Akselerasi. eJournal Psikologi, 2(2), 227-237.

Santrock, J. W. (2007). Remaja. Jakarta: Erlangga.

Silfa Agisni. S. (2017). Flow Akademik Siswa di SMP Negeri 9 Bandung. Skripsi. Bandung: Universitas Pendidikan Indonesia.

Slavin. R. (2011). Psikologi Pendidikan Teori dan Praktik. Edisi Sembilan Jilid 2. Jakarta: Indeks.

Susanto, H. (2006). Mengembangkan Kemampuan Self Regulation untuk Meningkatkan Keberhasilan Akademik Siswa. Jurnal Pendidikan Penabur, (7), 64-71.

Syah, M. (2012). Psikologi Belajar. Jakarta: PT Raja Grafindo Persada.

Syaiful Bahri Djamarah. (2011). Psikologi Belajar. Jakarta: Rineka Cipta. 